\title{
Control and Energy Management Strategy of Standalone DC Microgrid Cluster using PV and Battery Storage for Rural Application
}

\author{
Mohammad Aman Yaqobi ${ }^{*}$, Hidehito Matayoshi ${ }^{1}$, Mir Sayed Shah Danish ${ }^{1}$, Naomitsu Urasaki $^{1}$, Abdul \\ Motin Howlader ${ }^{2}$ and Tomonobu Senjyu ${ }^{1}$ \\ ${ }^{1}$ Department of Electrical and Electronic, University of The Ryukyu, 1 Senbaru, Nishihara, Okinawa, 903-0213, \\ Japan \\ ${ }^{2}$ Hawaii Natural Energy Institute, University of Hawaii, Mohoa, Honolulu, Hawaii 96822, USA \\ Email: aman319431@yahoo.com
}

\begin{abstract}
The recent evolution in technology and lifestyle has been led to a dramatic increase in electricity demand so that the local communities are encountered with challenges of huge initial costs, and sustainable extension to a national grid. Here in this paper, a DC microgrid cluster with three small areas (A, B and C) is proposed. Control and power stability of small-scale electrical system using renewable resources is a big challenge. In this study, the operation of DC microgrid and behavior of the system at different operating conditions is evaluated under different condition of the solar radiation and temperature changes for specific time periods. The DC Converters with PI control strategies are integrated to control the system performance and load-power balancing. The DC bus voltage level is employed as an information carrier for controller to maintain operation stability, improve efficiency, and enhance the redundancy of a system. At the meanwhile, the Maximum Power Point Trucking Incremental Conductance (MPPT-IC) algorithm is applied to maximize the efficiency and regulate the output voltage of the PV system to desired DC bus voltage. The PV arrays with battery and bidirectional converter are simulated to overcome the intermittency problems of PV outputs. Some typical operation modes are simulated using MATLAB ${ }^{\circledR} /$ Simulink to confirm the proposed model preference compared to the literature.
\end{abstract}

Keywords: DC microgrid, storage system, interfaced converters, PI control strategy, rural electrification.

\section{Introduction}

Microgrid is a localized interconnection of distributed energy resources, storage units and loads. Generally, microgrids are sub-categorized into three types: AC, DC, and hybrid. Each microgrid contains distributed micro source, energy storage system, load components, interfaced converters and control system [1]. Also, the technologies of distributed renewable energy resources as a standalone microgrid are identified as a potential solution for addressing rural electrification and also have several applications in automotive industries, marine technologies and communication centres. The main advantages of microgrids are no transmission loss, electrification of isolated area with low initial costs, and improving power system stability. In microgrids different types of distributed energy sources, such as fuel cell, wind turbine, photovoltaic and micro turbines are considered. In DC microgrid concept the distributed generators, loads, storage system and other components are connected together through DC bus and power electronic circuits, the only requirement to consider is DC bus voltage and internal power balance, regardless of reactive power problems, harmonics, and frequency control, which makes the control and components connection easier and improve system stability. Many studies have been carried out the overall power balance control strategies of DC microgrids which can be classified into three categories: centralized, decentralized, and distributed control [2-4]. The decentralized method operates only based on local measurement data. The lack of information from other units may result an inaccurate decision, reduced stability, and loss of optimal operation of the system. A central controller acquires system data, then makes the control decisions and schedules tasks. In centralized control, power lines are used as only communicating channels. 
Compared with AC microgrid, one of the fundamental property of DC microgrid is fewer conversion stages. Furthermore, Integration of PV systems in AC electrical network requires many inverters and can produce harmful harmonics which has negative impact on system operation and stability. In addition, for appropriate planning of a PV system as isolated microgrid, the most primary concerns are availability of desired solar radiation, variety of performance, safety, cost and applicability consideration including other factors that can influence the performance of a PV system [5]. However, the intermittent behaviour of the solar radiation makes the PV output uncertain, but due to power electronic facilities and decreasing initial cost in recent years, it changed the most abundant, clean and major renewable DG sources which are widely used in microgrid [6]. A DC system with localized and distributed resources can operate and feed power from $\mathrm{DC}$ and $\mathrm{AC}$ power sources efficiently with reliable performances. Additionally, regulating from $\mathrm{AC}$ to $\mathrm{DC}$ is quite easy and cheap compared to DC- AC conversion, which associated with a complex and expensive process, also the total energy conversion loss of AC to DC for DC load supply is approximately 10-25\% [7-9]. To solve these issues, world is moving toward DC appliances as most of electronic devices and sensitive loads are accept DC power supply. DC system are suitably admired due to their high efficiency, consistency, reliability, and load sharing performance when interconnected to DC renewable sources and storage system $[10,11]$. Moreover, application of DC microgrid for remote village communities where extension of national grid require huge cost, long time, and transmission loss is cost and time efficient $[12,13]$. To overcome the intermittency problems of renewable resources, integration of storage system with power electronic circuits guarantying the stability and economic feasibility of network, and improve power quality, peak demand shaving, load-levelling, demand time shifting, energy cost savings, and security of power supply $[14,15]$. Many research efforts related to rural electrification and microgrid are conducted over the past decades. One of the reasons behind the blunt progress of rural and remote electrification is an enormous initial investment for network extension to isolated areas. Preferably at rural and remote communities, electricity is desired during the night time for critical demand supply such as lighting system, TV, fan, and other small electrical appliances. Due to availability and low cost of renewable resources and land, small-scale decentralized PV installation for rural areas and dispersed communities is preferred to meet the electricity demand remarkably effective than centralized infrastructure or national grid.

The technical and economic design of a low voltage DC microgrid for rural and remote applications in Bangladesh and South Africa is analysed in $[16,17]$. The proposed design is based on PV, battery, and Maximum Power Point Tracking (MPPT). The battery storage characteristics, demand forecasting, PV panel selection, battery sizing, wire selection for distribution system are discussed. This study found that a suitable standalone DC microgrid is the most optimal cost effective option for rural electrification. The techno-economic assessment of hybrid energy off-grid system for island area in Oman is analysed which is based on methodology involving the use of hybrid optimization model for electric renewable resources to overcome the intermittency issue and provide reliable and secure supply in order to meet the demand at the least possible cost. In this work technical and economic feasibility of renewable energy integration, analysis of load demand profile and assessment of renewable energy resources for island area were conducted. The optimization results indicated that diesel, PV and wind generator as a hybrid system provides a sustainable power for remote areas, but it has the highest capital cost among other considered scenarios [18]. The detail design and operation of PV and battery DC-DC converters as a standalone DC microgrid for remote community application is discussed in [19- 21]. In these papers battery is considered as the main components for keeping DC bus voltage constant by charging and discharging functions. This system is tested in different operation modes and results show the control system and energy management system work properly. In [22], the cost effectiveness of a mini-grid, based on renewable energy resources utilization is discussed. This study reflects five years' experience related to mini and microgrid using renewable energy resources in South Asia. As a result, authors concluded that universal electrification is not viable just reliance on grid extensions without off-grid electrification, in which local grid-based supply would play a leading role in the future. A distributed optimal control and power control of DC microgrid using DC bus signalling is analysed in [23,24]. In these papers the Optimal Power Flow (OPF), four operation modes of power management system, control methods of DC converters in a stand-alone DC microgrid is investigated. In addition, an automatic control method for PV converters is proposed to realize smooth switching between constant voltage operation and MPPT operation. It enables DC 
bus voltage regulation capability of PV converters to maintained power balance of DC microgrid under different conditions.

In [25-27] the modelling and load scheduling simulation of PV and battery as an isolated DC microgrid is discussed. Here the operation of microgrid, performing load levelling, and voltage regulation in local power system is demonstrated. Battery energy storage is effectively complemented to the system for compensation of PV power fluctuation when subjected to sudden changes of solar irradiation. This paper will focus on the voltage and power stability of a standalone DC microgrid cluster to supply remote village communities by integration of a non-conventional source of energy such as PV array with a local load and battery system with various modes of operation. Proportional-Integral (PI) control strategy is used to control the power balance and voltage of DC microgrid because of their zero steady-state error, easily tuned coefficient and robustness. In order to implement the proposed control scheme, each converter is controlled to perform a different mode of operation. The operation mode is determined by switching signal, which is scheduled by control strategy resulting to optimize the cost and size of the system components. The rest of the paper is organized as follows: Section II deals with the structure of the proposed DC microgrid scheme and components designs. In sections III, and IV the applied methodology, results finding and discussions are pointed out. At last, the study is concluded with main finding and contributions in section $\mathrm{V}$.

\section{Proposed Standalone DC Microgrid Cluster Scheme}

In order to verify the correct functionality of the proposed DC microgrid, a dynamic model of the system is analysed. This system contains three small areas (A, B and C) with interconnected PV module, battery storage, DC loads and power electronic circuit as shown in Fig 1. Each of the system components has different voltage and current rating levels. Therefore, power converters are interfaced to regulate the DC bus voltage and power-sharing within neighbour areas. The PV power generation, battery capacity and the total DC load of the proposed system are listed in table 1. Since voltage instability and system floatation are the main indicators of power quality with a significant influence at normal operation. Therefore, low voltage distribution network should supply the load at an acceptable voltage range for efficient and economical operation. The US National Electrical Code (NEC) recommends a $5 \%$ voltage drop for feeders and branch circuits for a low to a medium distribution system. For this study, a tolerance of $400 \pm 20 \mathrm{~V}$ for DC bus voltage is supposed. Also because of the low population density in rural areas along distribution feeder is required for customer connections, it causes a high voltage drop, power loss, and uneconomical costs. Also, considering technical, and economic benefits of LV-DC system, it has better transmission capacity compared to LV-AC system. In AC system the conductor is chosen according to peak value of current and delivered power is calculated based on RMS value, while in DC system power is delivered based on constant peak current value and due to lack of skin effect for DC system, DC line can deliver $\sqrt{2}$ time more power than AC one [28]. The proposed system can be applying for small village through two DC distribution circuits, the power demand can be converted to desired DC voltage by load side converters.

Loss reduction can be achieved through proper voltage level, feeder length, conductor size, optimal location of the storage system and solar panels. For adequate analysis of the system cost, losses and voltage drop; line impedance and feeders' length are also considered which are $0.14 \Omega / \mathrm{km}, 0.24 \mathrm{mH} / \mathrm{km}$ and $1.5 \mathrm{~km}$, respectively. Additionally, without storage and control system, the common DC bus voltage varies according to the variation of $\mathrm{PV}$ outputs in standalone MG. Therefore, the storage system with a bidirectional converter and appropriate controller is necessary to improve power quality, maintain the bus voltage, and decrease the duration of power outages. Since voltage fluctuation and drops have a significant influence on normal operation of electrical equipment especially for sensitive loads, and motors, the low voltage DC microgrid should supply the load at the voltage within ranges that allow the efficient and economic operation of equipment. So, the voltage drop is an important constraint in the distribution network, which can be calculated by the following equation:

$$
C_{m i l}=\frac{2 K L I}{V_{D}}
$$




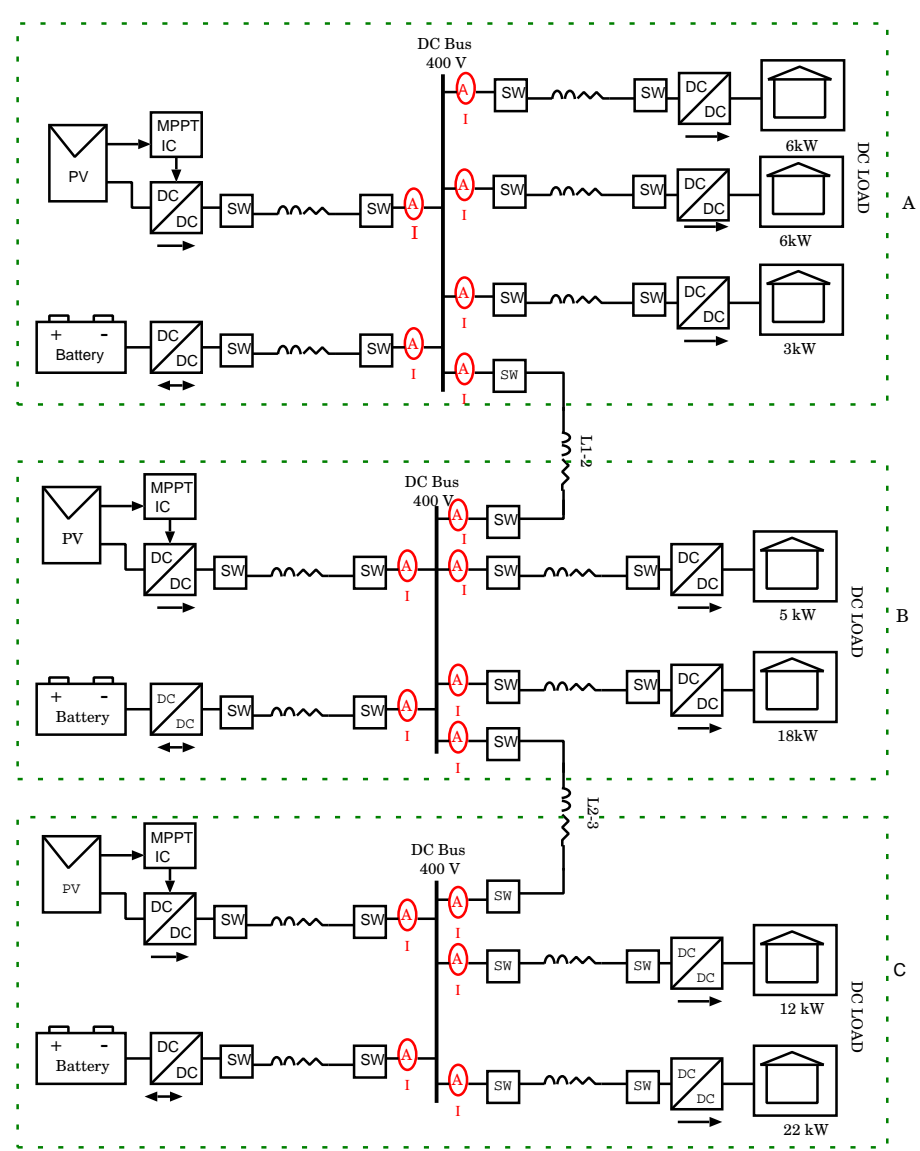

Figure 1. Schematic diagram of the proposed standalone DC microgrid cluster.

Where,

$\mathrm{K}$ is electrical resistivity of conductor in $\Omega-C_{\text {mil }} / f t,\left(K_{\text {Copper }}=12.9, K_{\text {Aluminum }}=21.2\right)$;

$\mathrm{I}$ is the load current;

$V_{D}$ is the maximum allowable voltage drop;

$\mathrm{L}$ is the one-way length of conductor in $\mathrm{ft}$;

$C_{m i l}$ is the cross section area of conductor.

The detailed description of the model of each subsystem is given below.

\subsection{Battery and Bidirectional DC-DC Converter}

Integration of storage system helps to improve the power quality and bus voltage stability. Several studies have proposed the integration of energy storage systems (ESS) to power grids with distributed generation and an effort to reduce the negative impacts and the necessity to invest in additional pick power plants and transmission infrastructure [29]. The battery as a backup system should be integrated with PV arrays via a DC-DC bidirectional converter to provide reliable and stable electricity by charging during non-peak load and discharging during peak load conditions with some fluctuations in generated power by renewable energy sources [30-32]. When comparing different types of batteries, lithium-ion battery is an appropriate choice for power storage applications, and it can deliver more power cycles in their lifetime [33]. A series and parallel connection of the Lithium-ion battery would make a high power battery matrix, which can be used easily in DC microgrid. The capacity of battery is selected to store all surplus energy from PV and efficiently supplying DC load at night and high demand time [34,35]. The power balance at any instant is expressed in below equation [36, 37]: 
Table 1. System parameters and components.

\begin{tabular}{lll}
\hline Parameters & Value & Symbol \\
\hline Power of $P V_{\max }$ & $90 \mathrm{~kW}$ & $P_{\text {pv-max }}$ \\
Battery capacity & $50 \mathrm{kWh}$ & $B$ \\
Maximum DC load & $72 \mathrm{~kW}$ & $R_{\text {load }}$ \\
DC Bus voltage & $400 \mathrm{~V}$ & $V_{\text {bus }}$ \\
Feeder length & $1.5 \mathrm{~km}$ & $L$ \\
Line resistance & $0.14 \Omega / k m$ & $R_{\text {line }}$ \\
Line inductance & $0.24 \mathrm{mH} / \mathrm{km}$ & $L_{\text {line }}$ \\
Switching Frequency & $5 \mathrm{kHz}$ & $F$ \\
\hline
\end{tabular}

$$
P_{B}(t)+P_{P V}(t)-P_{L}(t)+P_{\text {Loss }}=0
$$

The nominal voltage of the battery is $100 \mathrm{~V}$ in this paper. Bidirectional DC-DC interface converter with feedback PI controller is used as shown in Fig 2. The DC bus voltage is used as an indicator to determine the operation mode of converters according to the predefined threshold voltage. The complete operation of bidirectional converter contains two operation modes: charging (buck) and discharging (boost) modes. The mode of operation depends on switching signal which is generated by control system regarding to DC bus voltage fluctuation. By these process DC microgrid is able to maintain its stability of voltage and power. When sizing the battery as a storage system, two major parameters should be taken into consideration, the State of Charge (SoC) and Depth of Charge (DoC). Battery with a nominal capacity is permitted to charge and discharge to a specified limit. For power flow control in DC-DC bidirectional converter, an appropriate design of the controller is important. The feedback PI controller diagram for battery and converter operation is shown in Fig 3. It operates at two fixed voltages (the battery system voltage and DC bus voltage). Two PI controller with $K_{P}$ and $K_{i}$ equal to 0.02 and 110 for charging and $K_{P}$ and $K_{i}$ equal to 0.02 and 3 respectively for discharging mode is implemented to achieve the desired switching signal operation.

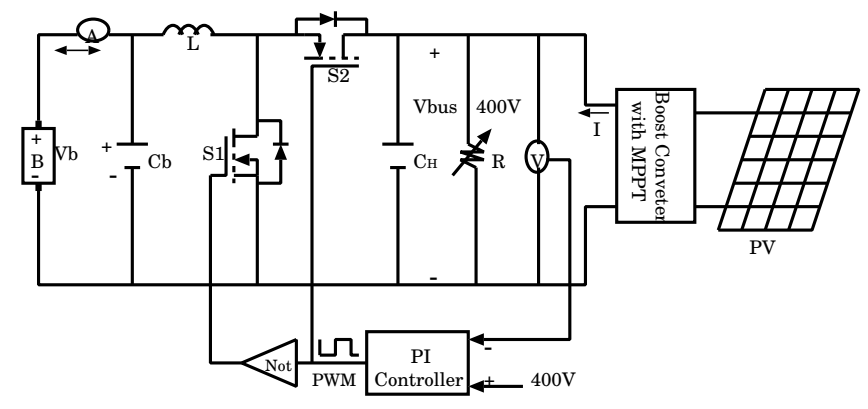

Figure 2. Circuit diagram of bidirectional DC-DC converter.

The controller compares the difference between bus voltage and reference value to obtain the battery charge and discharge comments. If the comparison value is negative, which means that the solar power is more than the total connected load, so the surplus power of PV modules has to be judiciously utilized by charging storage system if the SoC of the battery is less than $80 \%$, otherwise battery will not be charged to avoid the possibility of damage. When the value is greater than zero, which means the total load is greater than the combined power from solar panels. In such a situation, the control system checks the 
SoC of battery, the power of battery is used for load balance, if the SoC of battery is greater than $20 \%$. In a case the SoC is not greater than $20 \%$, the load shading should be performing to prevent the early aging of battery [38].

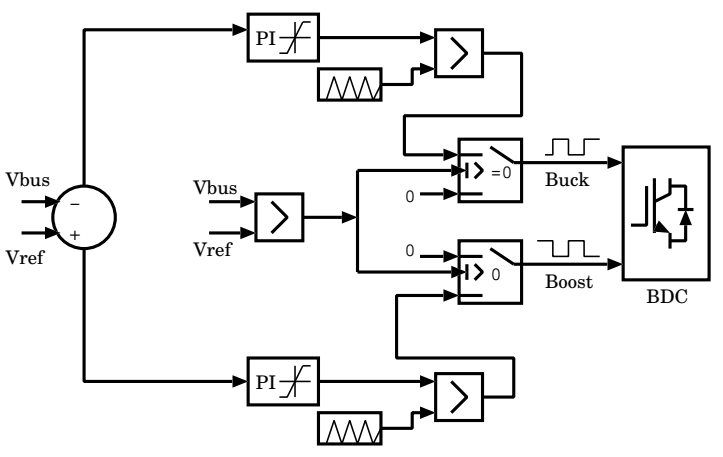

Figure 3. Control diagram of bidirectional converter.

In DC microgrid the load demand and power generated by renewable resources will be measured based on the conditions as follows:

- Case I: The load demand (PL) is equal to power generation (PG). In this condition, the generated power by PV modules is equal to the total load, hence the load will be supplied by the generation without any interruption.

- Case II: The load demand is less than generated power. In such a situation the excess power is charged in battery with consideration of SoC of the battery.

- Case III: The Load demand is more than generated power. This condition will be treated with caution to balance the load supply and power generation with the help of the battery storage system. Also, the difference in power generation and load demand will be calculated, then whether the available generation is enough to meet the priority load will be checked and the demand will be supplied until the SoC of the commercial load battery reaches a minimum level.

It will be charged when the system returns to case I condition. This process is continued to give uninterrupted power to consumers in small isolated areas. The state of charge of the battery has a positive slope during the time of charging and it has a negative slope during the time of discharging as shown in Fig 13.

\subsection{PV Module and DC-DC Boost Converter}

The photovoltaic array consists of PV modules which are connected in series and parallels according to the required voltage and power ratings. Each module consists of numbers of series and parallel connected PV cells. For close correlation with the hardware system, a single-diode solar PV cell is developed as shown in Fig 4. Single diode PV circuit is the most common mathematical representation of the solar module behaviour, it consists of a diode (D), temperature-radiation dependent photo-current source $\left(I_{L}\right)$, leakage current and voltage drop which are represented by parallel resistance $\left(R_{P}\right)$ and series resistance $\left(R_{S}\right)$ respectively. The basic equations of the circuit showing the dependence of the solar cell to environmental conditions are given below [39].

$$
\begin{gathered}
I=I_{L}-I_{0}\left[e^{\frac{V+I R_{S}}{K T}-1}\right] \\
I_{L}=\frac{\phi}{\phi_{r e f}}\left[I_{L-r e f}+\mu_{S C}\left(T_{C}-T_{C-r e f}\right)\right]
\end{gathered}
$$




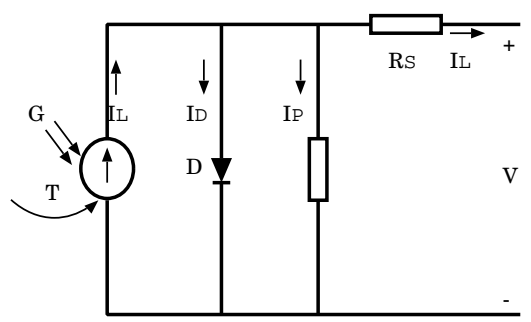

Figure 4. Equivalent circuit of one diode model of the PV cell.

$$
\begin{gathered}
I_{O}=I_{O-r e f}\left(\frac{T_{r e f}+273}{T+273}\right)^{3} e^{\left[\frac{N_{S-e g a p}}{q \alpha_{r e f}}\left(1-\frac{T_{r e f}+273}{T+273}\right)\right]} \\
I_{O-r e f}=I_{L, r e f} e^{\left[-\frac{V_{O C, r e f}}{\alpha_{r e f}}\right]}
\end{gathered}
$$

Where:

I is the net output current of PV cell (A);

$I_{L}$ is the light generated current $(\mathrm{A})$;

$I_{O}$ is the diode saturation current $(\mathrm{A})$;

$\mathrm{V}$ is the output voltage of cell $(\mathrm{V})$;

$q$ is the electron charge $\left(\left(1.602 * 10^{-19} C\right)\right)$;

$R_{S}$ is the series resistance of cell $(\Omega)$;

$R_{P}$ is the parallel resistance of cell $(\Omega)$;

$T$ is the cell operating temperature in Kelvin $(\mathrm{K})$;

$\mathrm{k}$ is the Boltzmann's constant $\left(1.381 * 10^{-23} \mathrm{~J} / \mathrm{K}\right)$;

$\phi$ is the solar irradiation $\left(W / m^{2}\right)$;

$V_{O C}$ is the cell open circuit voltage $(\mathrm{V})$;

$\alpha_{\text {ref }}$ is the thermal voltage factor $(\mathrm{V})$;

$\mu_{S C}$ is the T-coefficient for SC current $\left(\left(A /{ }^{\circ} C\right)\right)$;

$e_{\text {gap }}$ is the band gap energy of material $(1.17 \mathrm{eV}$ for $\mathrm{Si})$.

Mathematically the output power of PV modules is obtained by solar irradiance with respect to PV module surface area. The output power of PV panel is determined by following equations [40]:

$$
\begin{gathered}
P_{P V}=N A \mu_{g} \phi \\
\mu_{c d}=\mu_{\text {ref }}\left[1-\beta\left(T-T_{\text {cell-ref }}\right)\right] \\
T_{C}=\left[\frac{N C O T-20]}{800}\right] \phi_{t}+T_{a} \\
T_{I}=I_{D} R_{D}+R_{r}\left(I_{d}+I_{b}\right)
\end{gathered}
$$

Where:

A is the module surface area $\left(m^{2}\right)$;

$\mu_{g}$ is the generation efficiency;

$\mathrm{N}$ is the number of PV modules;

$\phi_{t}$ is solar radiation in tilted module $\left(W / m^{2}\right)$;

$\mu_{c d}$ is the power conditioning efficiency;

$\mu_{r e f}$ is the reference module efficiency;

$\beta$ is the temperature co-efficient $((0.004-0.006) / \mathrm{C})$; 
$T_{\text {Cell-ref }}$ is the reference cell temperature of modules;

NCOT is the nominal cell operating temperature;

$T_{I}$ is the total radiation in the solar cell considering normal and partial radiation.

Single PV cell of any rating will not be able to generate the required power levels. Hence, several PV cells are interconnected through a series and parallel combinations that scale up to generate the required PV power. The voltage and current are obtained by scaling up of PV modules, which is expressed as:

$$
\left.\begin{array}{c}
I_{\text {array }}=\frac{N_{P}}{I_{\text {module }}} \\
V_{\text {array }}=N_{S} V_{\text {module }} \\
P_{\text {array }}=V_{\text {array }} * I_{\text {array }} * F F C
\end{array}\right\}
$$

Where FF is filled factor of the ideal PV module without resistive effects. Here due to the variation of solar radiation and temperature, $\left(400<r<1000 ; 10<T<30^{\circ} \mathrm{C}\right)$ as an input of PV arrays, the output voltage of PV panels is low and will be affected. PV arrays are connected to DC bus through boost converter with $5 \mathrm{kHz}$ switching frequency and MPPT controller to adjust the voltage at bus side as shown in Fig 5. This converter has two main rules in the system: first, it increases the output voltage of PV to the DC bus voltage; secondly, it always works in MPPT mode in order to extract maximum available power from PV sources. Meanwhile, MPPT-IC as an electronics system that varies the electrical operation point of the module to find the optimal points is used to regulate the switching signal of the boost converter. During power imbalance due to fluctuation of solar radiation, the switching signal is adjusting by PI regulator using synchronous measurement of PV voltage and current, and the maximum power point tracking is maintained by preventing deviation of the control range of duty cycle [41]. The PI controller with $K_{P}$ and $K_{i}$ values of 0.002 and 0.2 is used for boost converter. The controller gives a value between 0 and 1 as an output for the switch operation and duty cycle.
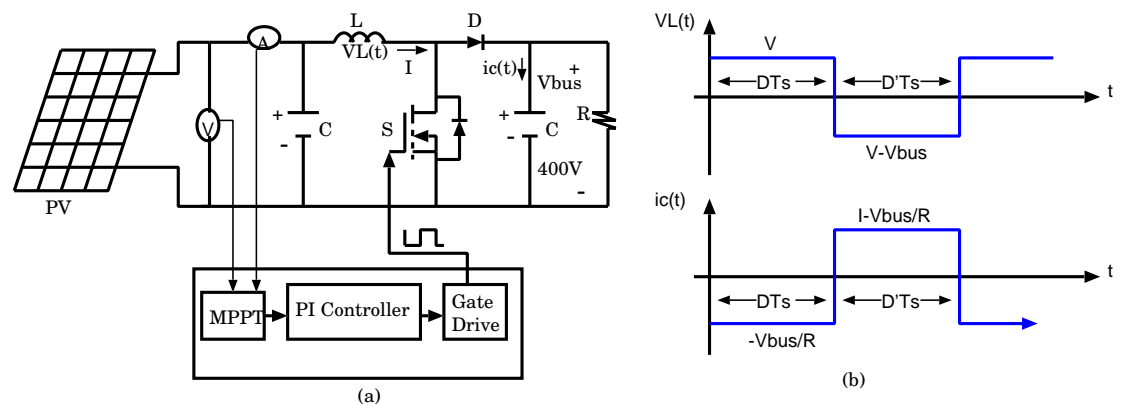

(b)

Figure 5. (a) Circuit diagram of boost converter and MPP controller; (b) V-I graph

This converter has two intervals of boost operation during continuous conduction mode, the steadystate analysis of inductor volt-second balance and capacitor charge balance have to study in both intervals. Then by applying a small ripple approximation, $V, V_{b u s}$, and $\mathrm{D}$ values, the desired boost converter can be easily designed as per requirements.

- Subinterval I: During this subinterval, the MOSFET (S) is conducting and the diode is reversely biased. By applying a small ripple approximation where $V_{\text {bus }}$ is the steady state output voltage:

$$
\begin{gathered}
I_{C}=-\frac{V_{b u s}}{R} \\
V_{L}=V_{b u s}
\end{gathered}
$$

- Subinterval II: In this subinterval, the MOSFET $(\mathrm{S})$ is in off state where the diode is forward biased. Once again by applying small ripple approximation; 


$$
\begin{gathered}
I_{C}=I-\frac{V_{b u s}}{R} \\
V_{L}=V-V_{b u s}
\end{gathered}
$$

Combining equations 12-15, a graph for $v_{L(t)}$ and $i_{C(t)}$ vs time can be obtained as shown in Fig 7 (b), where, $\mathrm{D}=$ duty cycle, $T_{S}=$ switching time period, $D^{\prime}=(1-D)$. By inductor volt-second balance the voltage across the inductor is;

$$
\begin{gathered}
L(t) d t=D V T_{S}+\left(V-V_{b u s}\right) T_{S} D^{\prime} \\
V_{b u s}=\frac{V}{D}
\end{gathered}
$$

The inductor current during subinterval I by considering the inductor ripple current $\left(\Delta i_{L}\right)$ is ;

$$
\begin{gathered}
d i(t) / d t=V_{L}(t) L=V / L \\
d i(t)=2 \Delta i ; d t=D T_{S}
\end{gathered}
$$

From equations (16)-(19) $\Delta i=V D T_{S} / 2 L$;

$$
\begin{gathered}
d V_{C}(t) / d(t)=i_{C}(t) C=-V / R C \\
\Delta V_{C}=\frac{D T_{S} V_{\text {bus }}}{2 C R}
\end{gathered}
$$

In the P-V curve, the characteristic of PV panels with an optimal power point (MPP) is shown in Fig 6. The efficiency of PV at this point is maximum. Because of the low operating efficiency of PV panels (maximum 20\%), so it is desirable to shift the operating point of $\mathrm{PV}$ at optimal point to deliver maximum power to load under varying solar radiation and temperature conditions. In this paper, the MPPT-IC algorithm is applied to regulate the PWM control signal of the DC-DC boost converter until the condition $I / d V+I / V=0$ is satisfied. Also, it copes with solar radiation, which changes every moment and maximizes the efficiency of PV system. Incremental conductance(IC) works based on observation of the P-V curve shown in Fig 7, that is one of the important technique as a tracking control strategy for integration of PV system [42]. 

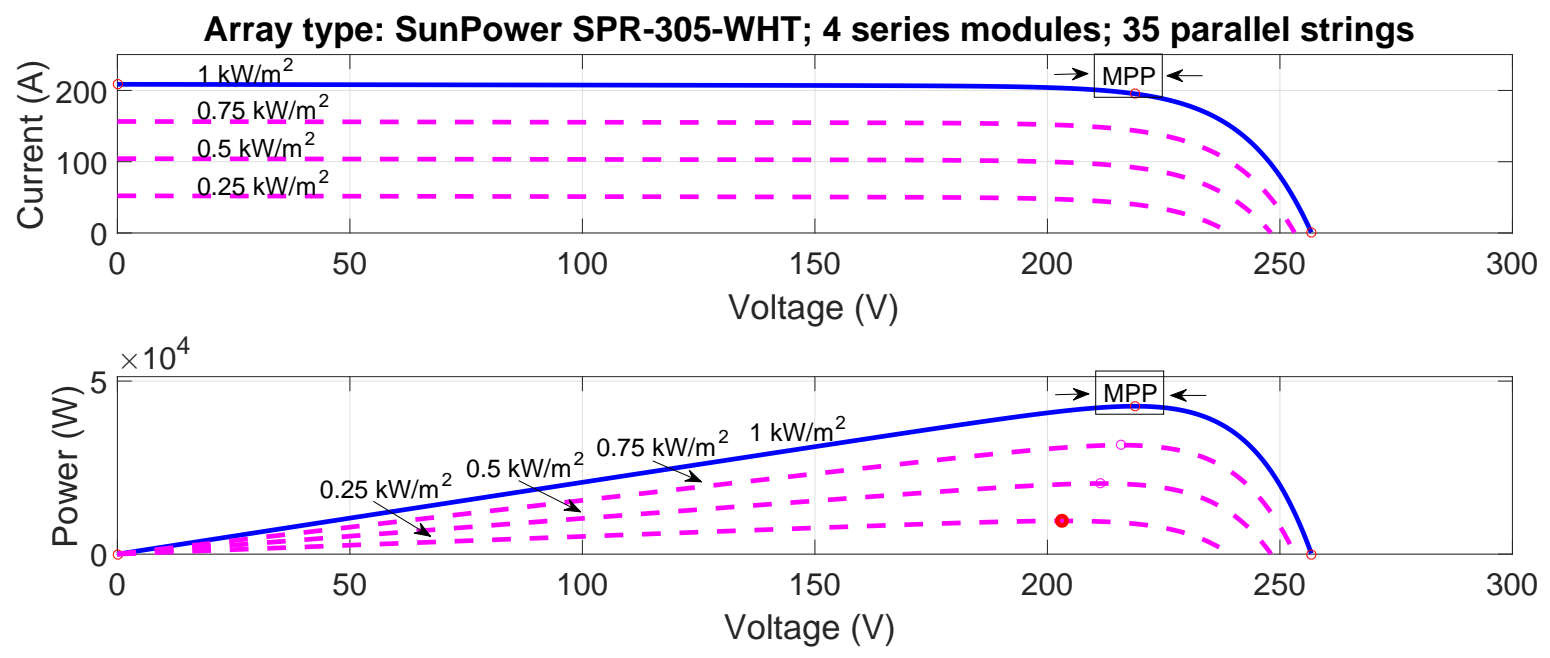

Figure 6. PV cell main characteristics (a)I-V characteristic of the solar panel. (b) P-V characteristics of PV panel.

This algorithm checks for the MPPT by comparing $d I / d V$ against $-I / V$ until it reaches the voltage operating point that incremental conductance is equal to the source conductance.

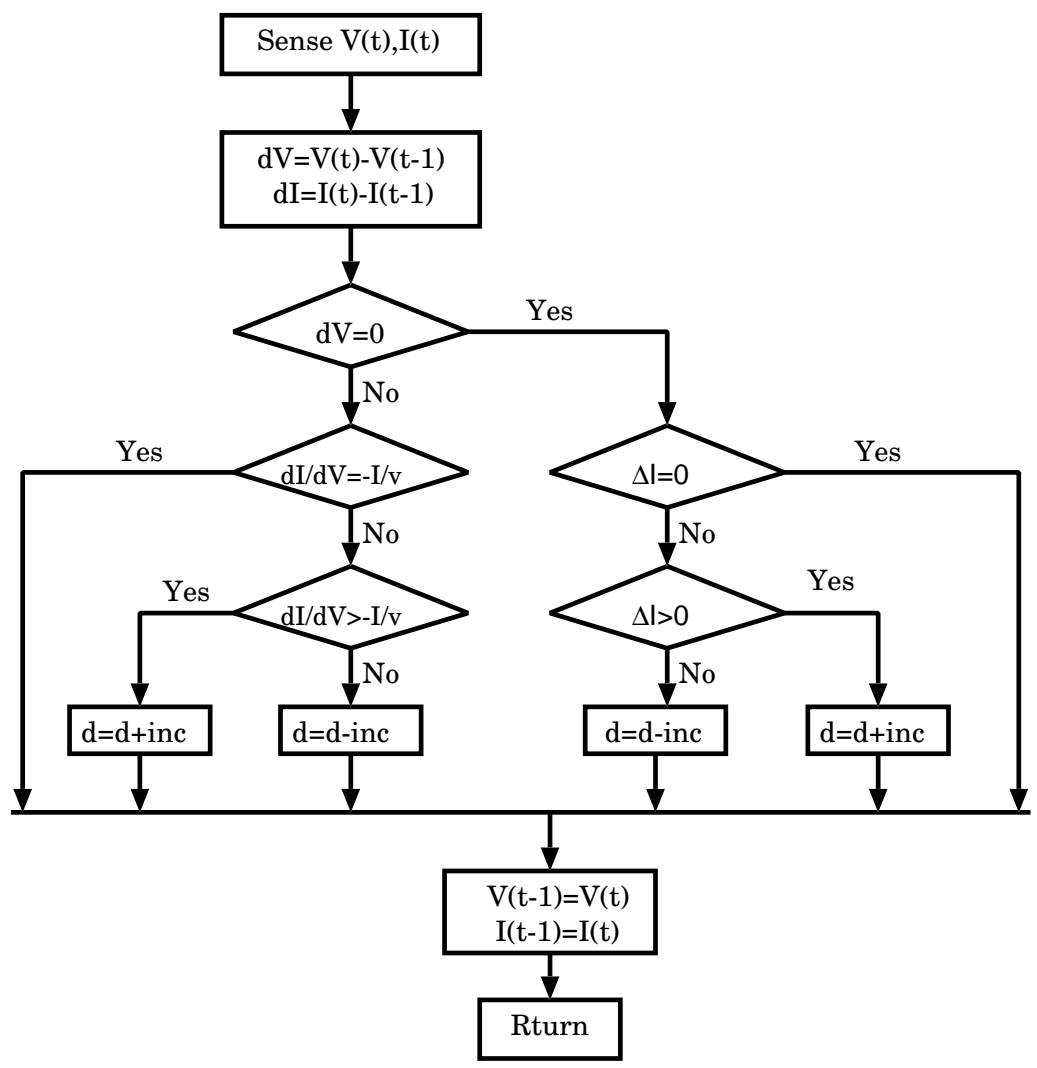

Figure 7. Flow chart of IC algorithm. 


\section{Simulation Results}

The performance of proposed standalone DC microgrid scheme is evaluated and analyzed to confirm the system stability. Voltage fluctuation of each area as a signal carrier is used to perform load and power management. The operation of proposed DC microgrid is illustrated in Figs 8-13. The nominal voltage of the $\mathrm{DC}$ bus was set at $400 \mathrm{~V}$ with $\pm 5 \%$ voltage fluctuation. Fig 8 illustrates the bus voltage at source and load side. Because of voltage drop in distribution line the bus voltage decreased to $388 \mathrm{~V}$ at load side, it is an appropriate voltage level for efficient operation of electrical components. Fig 9 reveals the variable PV power according to solar irradiance and temperature variations. Meanwhile, the boost converter integrated with PV system increased and stabilized the output voltage of modules which is low and unstable as shown in Fig 10. Appropriate DC converters and feedback PI controller is the most promised and simple way to overcome the instability and control challenges of small-scale electrical network using renewable resources.

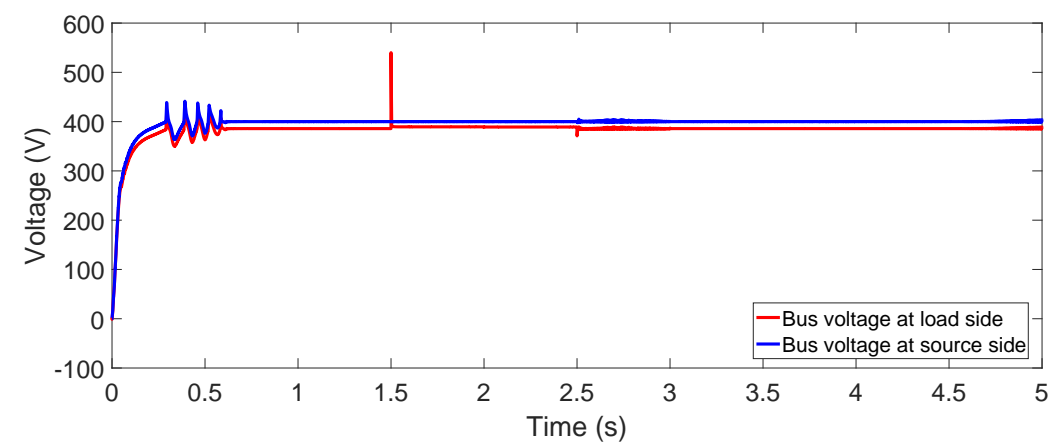

Figure 8. DC bus voltages.

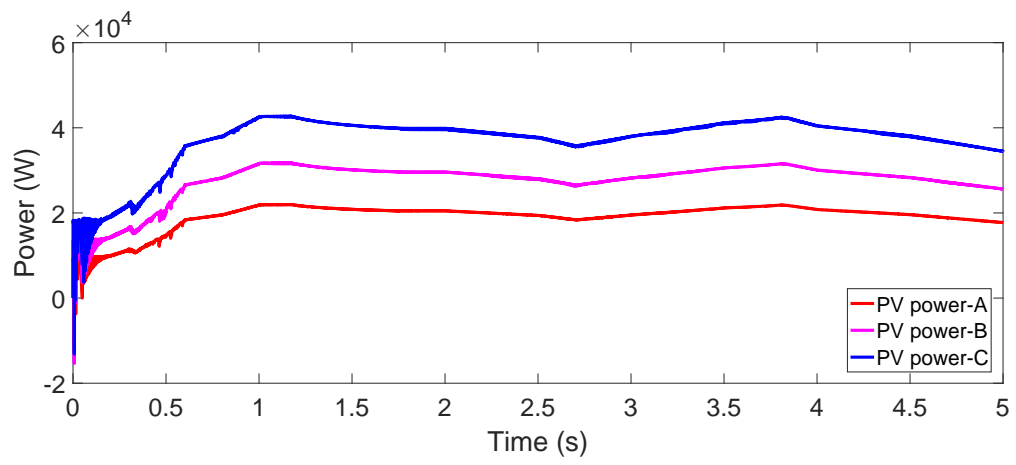

Figure 9. Output power of the PV. 


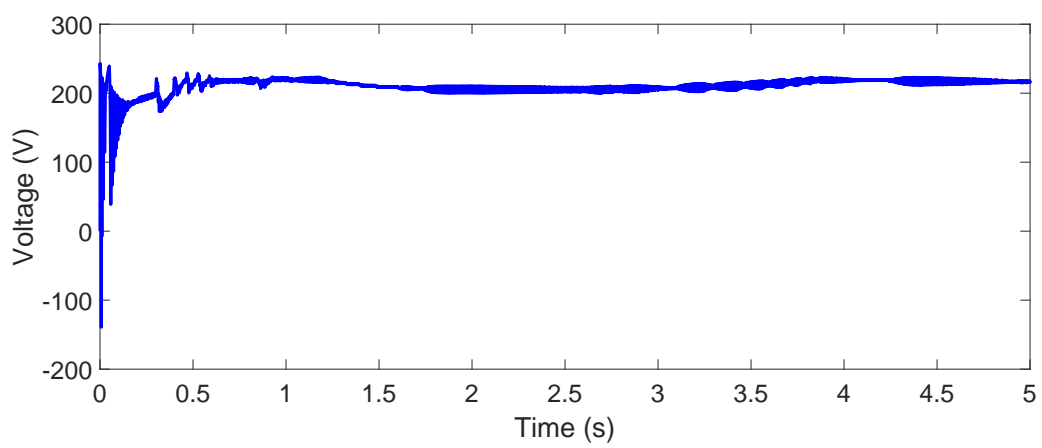

Figure 10. PV output voltage.

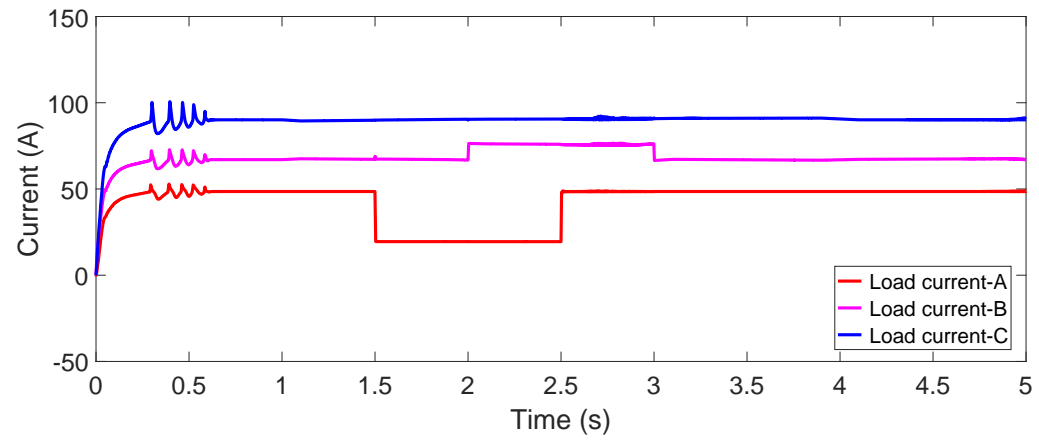

Figure 11. Total load currents.

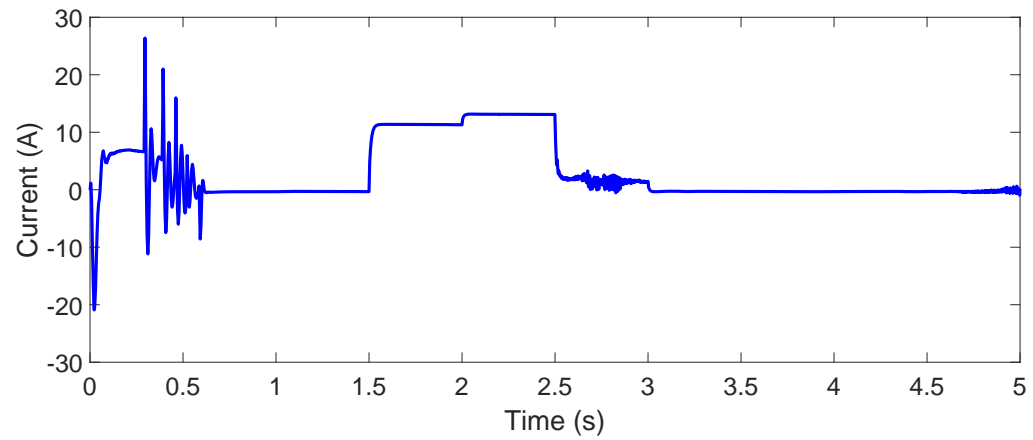

Figure 12. The current flow from area A to B. 


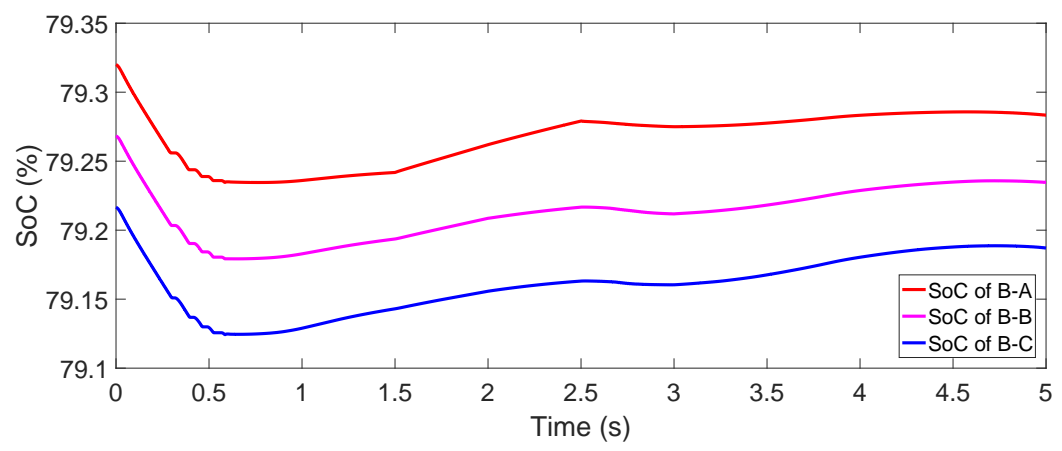

Figure 13. SoC of battery during different mode of operation.

\section{Discussion and Analysis}

The renewable energy management algorithm and controller for voltage fluctuation and power stability has been successfully implemented through the above discussed DC microgrid design. The simulation results show the accuracy of the proposed methodology for the sustainable operation of microgrid. It can be seen that the power of PV panels varies according to environmental conditions and its total peak value reaches to $90 \mathrm{~kW}$. In addition to this, for verifying the effective utilization of solar PV power, an IC algorithm is implemented to track the maximum power because of its zero steady-state error, easily tuned coefficient and robustness under abrupt changes of environmental conditions. At the beginning due to low sunshine, the PV generation cannot supply the load demands, thus the battery is discharging its initial charge rapidly to balance the power and load demand. After 1s the PV output increased and produced surplus power, which is utilized for charging the battery and maintain the DC bus voltage at $400 \mathrm{~V}$. The situation between 1.5s and $3 \mathrm{~s}$ is the witness of the load changed in area $\mathrm{A}$ and $\mathrm{B}$ which causes power injection from neighbour areas to meet the power-balance. At $1.5 \mathrm{~s}$ load demand in A is decreased rapidly which causes a ripple in bus voltage, increase the current flow from area A to B and C, causes the rapid increase of SoC of battery in A, as shown in Figs 11-13. At 2.5s the load connects back in area A, the SoC starting to decrease. After $2 s$ the load is increasing in area B resulting more current flow from $\mathrm{A}$ and decrease current flow from B to C. At the end of the simulation, battery start again to discharge due to decrease in PV output. The state of charge of the battery has a positive slope during charging mode, while it has a negative slope when discharging. In each situation the local and common DC bus voltage is used as the main signal carrier for controller and power management is performed proportionally to the voltage deviation of each small area.

\section{Conclusion}

In this paper, a PI-based control strategy for a PV-Battery isolated DC system is proposed to extract maximum power from PV and charge the battery optimally for rural applications. The proposed method makes the system simple and easy to control and also it is designed and tested effectively for various test conditions. Additionally, renewable energy management algorithm is considered to maintain a sustainable power balance and optimize power components in a DC microgrid cluster under consideration. The system exhibits how a renewable source of energy such as PV array can work together with a battery in DC microgrid to supply the local load demands. The main advantage of the proposed DC microgrid is supplying the load with the depth penetration of renewable energy sources rather than the conventional generator. The system is scalable to satisfy the load demand in rural communities and it is able to handle the load-power balancing for all the capricious cases $(P G>P L, P G=P L$ and $P G<P L)$ and provides a continuous supply for rural communities. In normal condition, each area of the system can meet all their energy demands with low-cost, local non-polluting renewable energy sources, thereby optimizing the utilization of renewable energy, reducing the total capacity of batteries (which inherit significant 
investment), and improving the system stability. The simulation studies of DC microgrid with proposed control system clearly indicate the power dissipation to the consumer through maximum renewable energy penetration and batteries without any divergence in the system. It is expected to electrify the rural and remote areas with minimum initial \& maintenance cost, conversion, and distribution losses by maximum penetration of renewable energy sources and storage systems. It can be inferred from the above results that regulated output voltage is maintained effectively without interruption to the consumer. Also the life and efficiency of the battery improved well by properly monitoring SoC conditions of the battery.

Acknowledgments. This research was funded by the Japan International Cooperation Agency-JICA. The authors express their gratitude for the support of the University of the Ryukyus through, Department of Electrical \& Electronics Engineering of Ryukyu University and Japan government.

\section{References}

1. S. Anand and B.G. Fernandes, "Steady state performance analysis for load sharing in DC distributed generation system," 10th International Conference on Environment and Electrical Engineering (EEEIC), Rome, Italy, pp.1-4, 2011.

2. T. Dragicevic, X. Lu, J.C. Vasquez, and J.M. Guerrero, "DC Microgrids-Part I: A Review of Control Strategies and Stabilization Techniques," IEEE Transaction on Power Electron, vol. 10, pp. 4876-4891, 2016.

3. T.T. H. Ma, H. Yahoui, and N. Siauve, "A Control Strategy of DC Building Microgrid Connected to the Neighborhood and AC Power Network," MDPI, vol. 42, pp. 1-17, 2017.

4. A. Tani, M.Camara and D. Brayima, "Energy management in the decentralized generation system based on renewable energy-ultracapacitors and battery to compensate the wind/load power fluctuations," IEEE Transaction on Industry Applications, vol. 51, no.2, pp. 1817-1827, 2014.

5. M.S. Danish, N.R. Sabory, G.A. Ludin, A. Yona, and T. Senjyu, "An open-door Immature policy for rural electrification: A case study of Afghanistan," International Journal of Sustainable and Green Energy, pp. 8-13, 2017.

6. A.Dizqah, A.Maheri, K.Busawon and A. Kamjoo, "A multivariable optimal energy management strategy for standalone DC microgrid," IEEE Transaction on Power System, vol. 30, no. 5, pp. 2278-2287, 2014.

7. J.J. Justo, F. Mwasilu, J. Lee, and J.W. Jung, "AC-microgrids versus DC-microgrids with distributed energy resources: A review," Renewable Sustainable Energy, vol. 24, pp. 387-405, 2013.

8. L. Gao, Y. Liu, H. Ren, and J.M. Guerrero, "A DC Microgrid Coordinated Control Strategy Based on Integrator Current-Sharing," Energies, vol. 10, pp. 1-17, 2017.

9. Z. A. Mohammad, and A. Gholamali, "EfiňĄcient utilization of renewable energy by smart DC Micro-grid," Journal of Applied Environmental and Biological Sciences, vol. 4, pp. 154-162, 2015.

10. X. Liu, P. Wang, and P.C. Loh, "A hybrid AC/DC microgrid and its coordination control," IEEE Transaction on Smart Grid, vol. 2, no. 2, 2011.

11. R. Weis, L. Ott, M. Szpek, and U. Boeke, "Energy efiňAzcient DC-grids for commercial buildings," In Proceedings of the 2014 IEEE 36th International Telecommunications Energy Conference (INTELEC), BC, Canada, pp. 1-8, 2014.

12. M. Sechilariu, B.C. Wang, and F. Locment, "Supervision control for optimal energy cost management in DC microgrid: Design and simulation," Int. J. Electr. Power Energy System, vol. 58, pp. 140-149, 2014.

13. G. Subramani, V.K. Ramachandaramurthy, S. Padmanaban, L. Mihet-Popa, F. Blaabjerg, and J.M. Guerrero, "Grid-Tied Photovoltaic and Battery Storage Systems with Malaysian Electricity Tariff-A Review on Maximum Demand Shaving," Energies, vol. 10, pp. 125-139,2017.

14. A. Nieto, V. Vita, L. Ekonomou, and N.E. Mastorakis, "Economic analysis of energy storage system integration with a grid connected intermittent power plant, for power quality purposes," WSEAS Transactions on Power Systems, Vol. 11, pp. 65-71, 2016.

15. S. Agamah, and L. Ekonomou, "Energy storage system scheduling for peak demand reduction using evolutionary combinatorial optimization," Sustainable Energy Technologies and Assessments, Vol. 23, pp. 73-82, 2017.

16. M. R. Khan, "A standalone DC microgrid for electricity supply in rural Bangladesh," Developments in Renewable Energy Technology, pp. 5-7, 2012.

17. G. M. Bokanga, A. Raji, and M. T. Kahn, "Design of a low voltage DC microgrid system for rural electrification in South Africa," Journal of Energy in Southern Africa, vol. 25(2), pp. 9-14, 2014.

18. H.M. Al Ghaithi, G.P Fotis, and V. Vita, "Techno-economic assessment of hybrid energy off-grid system - A case study for Masirah island in Oman," International Journal of Power and Energy Research, Vol. 1, No.2, pp. 103-116, 2017. 
19. M.K. Shahzad, A. Zahid, T. U. Rashid, M.A. Rehan, M. Ali, and M. Ahmad, "Techno-economic feasibility analysis of a solar-biomass off grid system for the electrification of remote rural areas in Pakistan using HOMER software," Renewable Energy, vol. 106, pp. 264-273, 2017.

20. F. Martin-MartÃnnez, A. SÃąnchez-Miralles, and M. Rivier, "A literature review of Microgrids: A functional layer based classification," Renewable Sustainable Energy Rev,vol. 62, pp. 1133-1153, 2016.

21. C. Dixon, S. Reynolds, and D. Rodley, "Micro/small wind turbine power control for electrolysis applications," Renewable Energy, vol. 87, pp. 182-192, 2016.

22. S. C. Bhattacharyya, and D. Palit, "Minigrid based off-grid electrification to enhance electricity access in developing countries: What policies may be required," Energy Policy,vol. 94, pp. 166-178, 2016.

23. Z. Wang, F. Liu, Y. Chen, S. H. Low, and S. Mei, "Unified distributed control of stand-alone DC microgrids," IEEE Transactions on Smart Grid, vol. 10, pp. 31-42, 2017.

24. L. Zhang, T. Wu, Y. Xing, K. Sun, and J. M. Gurrero, "Power control of DC microgrid using DC bus signaling," In Applied Power Electronics Conference and Exposition (APEC), Fort Worth, USA, pp. 6-11, 2011.

25. A. M. Dizqah, A. Maheri, K. Busawon, and P. Fritzson, "Standalone DC microgrids as complementarity dynamical systems: Modeling and applications," Control Engineering Practice, vol. 35, pp. 102-112, 2015.

26. N. Rajasekar, N. K. Kumar, and R. Venugopalan, "Bacterial foraging algorithm based solar PV parameter estimation," Solar Energy, vol. 97, pp. 255-265, 2013.

27. M. Z. C. Wanik, A. Bousselham, and A. Elrayyah, "Real-time simulation modeling for PV-battery based microgrid system," International Conference on Power System Technology (POWERCON), Wollongong, NSW, Australia, pp. 21-29, 2016.

28. Y. X. Wang, F. F. Qin, and Y. B. Kim, "Bidirectional DC-DC converter design and implementation for lithium-ion battery application," In Power and Energy Engineering Conference (APPEEC), Hong Kong, China, pp. 7-10, 2014.

29. A. Nieto, V. Vita, and T.I. Maris, "Power quality improvement in power grids with the integration of energy storage systems," International Journal of Engineering Research 65 Technology, Vol. 5, No. 7 , pp. 438-443, 2016.

30. R. J. Wai and R. Y. Duan, "High-efficiency bidirectional converter for power sources with great voltage diversity," IEEE Trans. Power Electron, vol. 22, no. 5, pp. 1986-1996, 2007.

31. M.K. AL-Nussairi, R. Bayindir, S. Padmanaban, L. Mihet-Popa, and P. Siano, "Constant Power Loads (CPL) with Microgrids: Problem Definition, Stability Analysis and Compensation Techniques," Energies, vol. 10. pp. 1-18, 2017.

32. S. Ganesan, S. Padmanaban, R. Varadarajan, U. Subramaniam, and L. Mihet-Popa, "Study and Analysis of an Intelligent Microgrid Energy Management Solution with Distributed Energy Sources," Energies,vol. 10, pp. 654-659, 2017.

33. G. S. Rao, K. H. Reddy, B.R. Teja, and B. Devasahayam, "Matlab based simulation model of standalone DC Microgrid for Remote Area Power Applications," International Journal of Engineering ETTechnology,vol. 7, pp. 153-157, 2018.

34. S.Y. Yu, H.J. Kim, J.H. Kim, and B.M. Han, "SoC-based output voltage control for BESS with a lithium-ion battery in a stand-alone DC microgrid," Energies, vol. 924, pp. 2-15, 2016.

35. N. Zhou, N. Liu, J. Zhang, and J Lei, "Multi-Objective optimal sizing for BATTERY Storage of PV-based microgrid with demand response," Energies, vol. 591, pp. 65-78, 2016.

36. V. T. Chetti, and G. Priyanka, "Design and simulation of stand-alone DC Grid for commercial building," International journal of latest trends in engineering and technology, vol. 7, pp. 531-538, 2016.

37. C. Kuei-Hsiang, T. Ming-Chang, H. Chun-Hao, L. Yang-Guang, and H. Liang-Chiao, "Design and implementation of a bidirectional dc-dc converter for stand-alone photovoltaic systems," International Journal of Computer, Consumer and Control, vol. 2, pp. 44-55, 2013.

38. M. Saleh, Y. Esa, Y. Mhandi, W. Brandauer, and A. Mohamed, "Design and implementation of CCNY DC microgrid testbed," IEEE Industry Applications Society Annual Meeting, Portland, USA, pp. 2-6, 2016.

39. S. R. Chafle, and U. B. Vaidya, "Incremental conductance MPPT technique FOR PV system," International Journal of Advanced Research in Electrical, Electronics and Instrumentation Engineering, vol. 2, pp. 2720-2726, 2013.

40. M. Gunasekaran, H. M. Ismail, B. Chokkalingam, L. Mihet-Popa, and S. Padmanaban, "Energy Management Strategy for Rural Community's DC Micro Grid Power System Structure with Maximum Penetration of Renewable Energy Sources," Applied Science, MDPI, vol. 585, no. 8, pp. 89-108, 2018.

41. M. Bhunia, and R. Gupta, "Voltage regulation of stand-alone photovoltaic system using boost SEPIC converter with battery storage system," In Engineering and Systems Students Conference (SCES), Allahabad, India, PP. 12-14, 2013. 
42. M. Lokanadham, and K. V. Bhaskar, "Incremental conductance based maximum power point tracking (MPPT) for photovoltaic system," International Journal of Engineering Research and Applications, vol. 2, pp. 1420-1424, 2012. 